\title{
Is There Good Simulation Basic Training for End-To-Side Vascular Microanastomoses?
}

\author{
Franck Marie P. Leclère $\cdot$ Mario Trelles • \\ Gregory A. Lewbart $\cdot$ Esther Vögelin
}

Received: 7 May 2012/ Accepted: 27 September 2012/Published online: 9 February 2013

(c) Springer Science+Business Media New York and International Society of Aesthetic Plastic Surgery 2013

\begin{abstract}
Background Microvascular anastomosis is the cornerstone of free tissue transfers. Irrespective of the microsurgical technique that one seeks to integrate or improve, the time commitment in the laboratory is significant. After extensive previous training on several animal models, we sought to identify an animal model that circumvents the following issues: ethical rules, cost, time-consuming and expensive anesthesia, and surgical preparation of tissues required to access vessels before performing the microsurgical training, not to mention that laboratories are closed on weekends.

Methods Between January 2012 and April 2012, a total of 91 earthworms were used for 150 microsurgical training exercises to simulate vascular end-to-side microanastomosis. The training sessions were divided into ten periods of 7 days. Each training session included 15 simulations of end-to-side vascular microanastomoses: larger than $1.5 \mathrm{~mm}$ $(n=5)$, between 1.0 and $1.5 \mathrm{~mm}(n=5)$, and smaller than $1.0 \mathrm{~mm}(n=5)$. A linear model with the main variables
\end{abstract}

F. M. P. Leclère $(\bowtie) \cdot$ E. Vögelin

Department of Plastic and Hand Surgery, Inselspital Bern,

University of Bern, Freiburgstrasse, Bern, Switzerland

e-mail: franckleclere@yahoo.fr; franck.leclere@inserm.fr;

franck.leclere@insel.ch

F. M. P. Leclère

INSERM, U 703 (French National Institute of Health and Medical Research), Université Lille Nord de France, Lille University Hospital-CHRU, Lille, France

M. Trelles

Department of Plastic Surgery, Antoni de Gimbernat

Foundation, Villafortuny, Cambrils, Spain

G. A. Lewbart

College of Veterinary Medicine, North Carolina State

University, Raleigh, NC, USA being the number of weeks (as a numerical covariate) and the size of the animal (as a factor) was used to determine the trend in time of anastomosis over subsequent weeks as well as the differences between the different size groups.

Results The linear model shows a significant trend $(p<0.001)$ in time of anastomosis in the course of the training, as well as significant differences $(p<0.001)$ between the groups of animals of different sizes. For microanastomoses larger than $1.5 \mathrm{~mm}$, the mean anastomosis time decreased from $19.3 \pm 1.0$ to $11.1 \pm 0.4$ min between the first and last week of training (decrease of $42.5 \%$ ). For training with smaller diameters, the results showed a decrease in execution time of $43.2 \%$ (diameter between 1.0 and $1.5 \mathrm{~mm}$ ) and $40.9 \%$ (diameter $<1.0 \mathrm{~mm}$ ) between the first and last periods. The study demonstrates an improvement in the dexterity and speed of nodes execution.

Conclusion The earthworm appears to be a reliable experimental model for microsurgical training of endto-side microanastomoses. Its numerous advantages are discussed here and we predict training on earthworms will significantly grow and develop in the near future.

Level of Evidence III This journal requires that authors assign a level of evidence to each article. For a full description of these Evidence-Based Medicine ratings, please refer to the Table of Contents or the online Instructions to Authors www.springer.com/00266.

Keywords Earthworms - Microanastomoses · Microsurgery $\cdot$ Experimental model

Microvascular anastomosis is the cornerstone of free tissue transfers [1-5]. Great progress has been made since the pioneering work of Jacobson and Suarez [6] in discovering factors that affect the patency of vascular microanastomoses. 
This progress stems from technical improvements in microsurgical devices, optical instrumentation, and especially in the training and education of microsurgeons [7]. Surgical education has traditionally been built on the Halstedian apprenticeship model, where experts teach skills to novices using real patients. Although well-established, this process comes with limitations and areas for improvement remain to maximize the educational benefit for residents and the safety of patients. This is especially true of microsurgery, where regular training is necessary and should be achieved in the laboratory before any clinical procedure is performed [8]. Several microsurgical training models are available that can impart skill and provide an appropriate level of training. Models range from basic devices [9] to live animals. However, the texture of inert models substantially differs from live clinical situations and the use of animal models is limited by ethical rules, cost, time-consuming and expensive anesthesia, and surgical preparation of tissues required to access vessels before performing the microsurgical training. Since 2010 we have been working toward developing an effective model to circumvent these difficulties and foster regular and easy accessible training. Based on the literature and our previous observations [10], we found that the earthworm is a reliable model for microsurgical training because of the following: (1) anesthesia is not required; (2) the texture of the earthworm is comparable to that of the arterial wall; (3) the wall tends to collapse, perfectly mimicking the behavior of mammalian blood vessels during anastomoses; (4) breeding earthworms is very easy and does not require expensive equipment; (5) their ubiquity makes it is possible to use animal sizes matched to the desired training difficulty; and (6) no assistance is needed, which facilitates regular training.

In this article we present a prospective series of microsurgical end-to-side anastomoses training with earthworms and discuss the numerous advantages but also the technical limitations of this animal model for basic microsurgical training.

\section{Material and Methods}

Animals

Between January 2012 and April 2012, a total of 150 microsurgical training exercises were performed on 91 Lumbricus terrestris (order Haplotaxida; phylum Annelida). The earthworms weighed between 1 and $8 \mathrm{~g}$. The mean length of the animals was $16 \mathrm{~cm}$ (range $=4-34 \mathrm{~cm}$ ). The training sessions were divided into ten periods of 1 week each and included 15 simulations of end-to-side vascular microanastomoses: larger than $1.5 \mathrm{~mm}(n=5)$, from 1.0 to $1.5 \mathrm{~mm}(n=5)$, and smaller than $1.0 \mathrm{~mm}$ $(n=5)$.

\section{Surgical Technique}

After killing the earthworms by immersion in $5 \%$ ethanol $[11,12]$, the body of the animal was sectioned proximally and distally. The animal was washed with a thin steel wire. Microvascular clips were placed at the level of the desired training. The microsurgical end-to-side training exercise was then performed using the biangulation technique. There were about ten sutures used in the group in which diameter was larger than $1.5 \mathrm{~mm}$ and eight sutures in the other two groups. Each exercise was performed by the same operator (FML).

\section{Objective Parameters}

The external diameter of the animal was measured with an eyepiece reticule at $\times 40$ magnification prior to division. The time from the first to the last suture was systematically recorded. An O'Brian patency test was not possible and was replaced by a permeability test conducted by injecting water into the earthworm using a syringe. Furthermore, a longitudinal incision allowed for visualization of the inner quality of the sutures for each microsurgical training exercise.

\section{Subjective Parameters}

A subjective evaluation was conducted by the expert surgeon at the end of the training by rating the following parameters as excellent, very good, good, and bad: dexterity, speed of nodes execution, improvement in the precision of movement, and improvement in the quality of microanastomoses.

\section{Statistical Analysis}

This prospective study involved 150 microsurgical training exercises performed on 91 earthworms spread over 10 weeks of practice, each with three subgroups based on the size of the animals. A linear model with the main variable the number of the week (as a numerical covariate) and the size of the animal (as a factor) was used to determine the trend in time of anastomosis over subsequent weeks as well as differences between the different size groups. A $p$ value of $<0.05$ was considered to be statistically significant. Statistical analysis was performed using the SPSS Stat program (SPSS, Inc., Chicago, IL, USA). Data are presented as mean \pm standard error of the mean (SEM). 


\section{Results}

Microsurgical training exercises (150 occurrences) were performed on 91 earthworms (Figs. 1, 2). All the microanastomoses were patent, as evidenced by our permeability test. The results are presented in Tables 1,2 .

\section{Anastomosis Time}

The results are presented in Table 1 . The linear model shows a significant trend $(p<0.001)$ in time of anastomosis in the course of the training as well as significant differences $(p<0.001)$ between the groups of different sizes.

For microanastomoses larger than $1.5 \mathrm{~mm}$, the mean anastomosis time decreased from $19.3 \pm 1.0$ to $11.1 \pm 0.4 \mathrm{~min}$ between the first and last week of training (decrease of $42.5 \%$ ). For training with smaller diameters, the results showed a decrease in execution time of $43.2 \%$ (diameter between 1.0 and $1.5 \mathrm{~mm}$ ) and $40.9 \%$ (diameter $<1.0 \mathrm{~mm}$ ) between the first and last periods.

\section{Subjective Parameters}

The subjective evaluation of training is presented in Table 2 . The study noted a subjective improvement for all subjective criteria, especially for the group in which size was $<1 \mathrm{~mm}$.

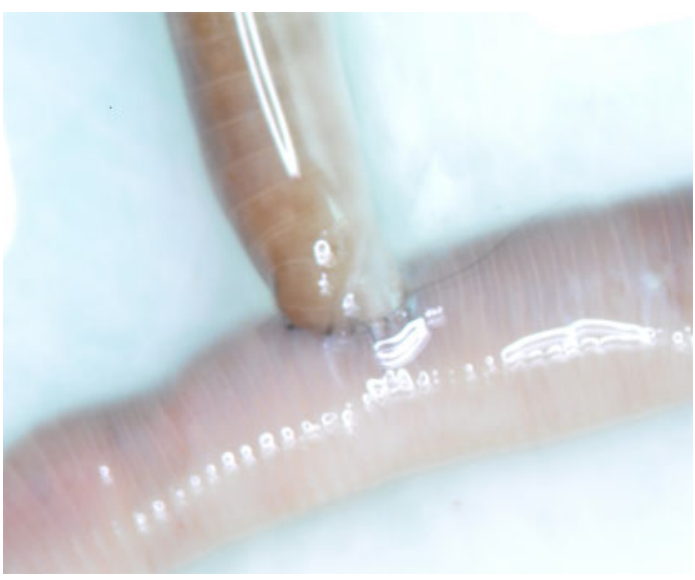

Fig. 2 Result after microsurgical end-to-side training (diameter $=2.2 \mathrm{~mm}$, magnification $\times 40$ ) and permeability test conducted by injecting water into the earthworm using a syringe

\section{Discussion}

Regular training is essential to acquire a sound foundation in microsurgery skills and should be done in the laboratory prior to performing clinical procedures. Basic microsurgical techniques are end-to-end and end-to-side microanastomosis but other techniques also deal with vessel size variations. These include invaginating anastomoses, fishmouth incision, oblique section, and wedge excision. Irrespective of the microsurgical technique, whether the purpose of training is to integrate new skills or improve on
Fig. 1 Microsurgical training using the biangulation technique. a Clamping the Lumbricus. b Dilatation of the smaller Lumbricus. c Placement of the two cardinal microsutures.

d Microanastomosis of the anterior wall

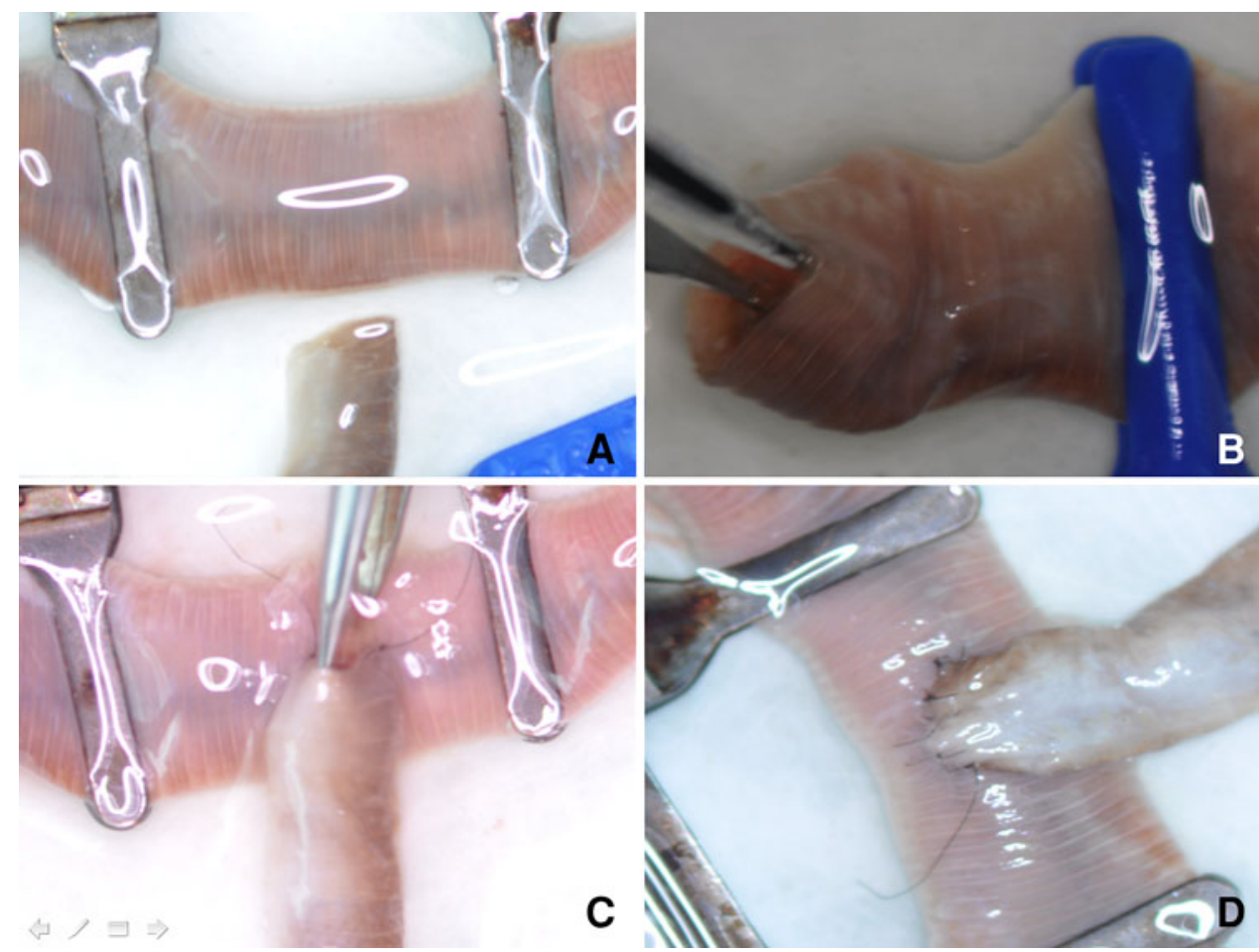


Table 1 Average time necessary for the training exercise in the different groups and periods of training

\begin{tabular}{llll}
\hline \multicolumn{4}{l}{ Time for training } \\
\cline { 2 - 4 } & $(\varnothing>1.5 \mathrm{~mm})$ & $(\varnothing=1-1.5 \mathrm{~mm})$ & $(\varnothing<1.0 \mathrm{~mm})$ \\
\hline 1 & $19.3 \pm 1.0$ & $19.9 \pm 1.3$ & $23.0 \pm 2.7$ \\
2 & $18.1 \pm 0.5$ & $19.1 \pm 0.7$ & $20.2 \pm 1.0$ \\
3 & $17.0 \pm 1.0$ & $18.8 \pm 0.6$ & $19.1 \pm 0.8$ \\
4 & $15.5 \pm 0.4$ & $16.5 \pm 1.2$ & $18.3 \pm 0.9$ \\
5 & $15.1 \pm 0.8$ & $16.2 \pm 1.0$ & $17.2 \pm 0.7$ \\
6 & $15.2 \pm 0.7$ & $16.0 \pm 0.8$ & $17.7 \pm 0.6$ \\
7 & $13.5 \pm 0.9$ & $13.9 \pm 0.6$ & $15.8 \pm 1.2$ \\
8 & $11.5 \pm 0.4$ & $12.2 \pm 0.7$ & $14.3 \pm 0.9$ \\
9 & $11.2 \pm 0.6$ & $11.4 \pm 0.3$ & $14.7 \pm 0.7$ \\
10 & $11.1 \pm 0.4$ & $11.3 \pm 0.4$ & $13.6 \pm 0.6$ \\
\hline
\end{tabular}

Values are mean \pm SD in $\min$

Table 2 Subjective evaluation of the end-to-side microsurgical training

\begin{tabular}{|c|c|c|c|c|}
\hline Criterion & Excellent & $\begin{array}{l}\text { Very } \\
\text { good }\end{array}$ & Good Bad & Remarks \\
\hline Dexterity & $X$ & & & $\begin{array}{l}\text { For all } \\
\text { groups }\end{array}$ \\
\hline $\begin{array}{l}\text { Speed of nodes } \\
\text { execution }\end{array}$ & $X$ & & & $\begin{array}{l}\text { For all } \\
\text { groups }\end{array}$ \\
\hline $\begin{array}{l}\text { Improvement in the } \\
\text { precision of } \\
\text { movement }\end{array}$ & $X$ & & & $\begin{array}{l}\text { Especially } \\
\text { for the } \\
\text { groups in } \\
\text { which size } \\
\text { was } \\
<1 \mathrm{~mm}\end{array}$ \\
\hline $\begin{array}{l}\text { Improvement in the } \\
\text { quality of } \\
\text { microanastomoses }\end{array}$ & & $X$ & & $\begin{array}{l}\text { This model } \\
\text { does not } \\
\text { assess any } \\
\text { intimal } \\
\text { injuries }\end{array}$ \\
\hline
\end{tabular}

existing ones, significant amounts of time must be invested, which conflicts with the constraints faced by residents [13, 14]. After extensive training on different animal models such as pigs, rats, rabbits, chicken, and fish [15], and also on discarded abdominoplasty specimens, we have been searching for a new model that can provide a solution to the following issues associated with basic training: ethical rules, cost, time-consuming and expensive anesthesia, and surgical preparation of tissues required to access vessels before performing the microsurgical training, not to mention laboratories that are closed on weekends.

In this prospective study, 150 microsurgical end-to-side microvascular training exercises were performed on 91 earthworms. The results underline an improvement in speed of execution and microsurgical dexterity for all sizes of animals. Our series objectively confirmed the numerous benefits associated with the annelid model for basic microsurgical training: (1) The storage of the animal is simple and inexpensive. (2) Their ubiquity makes it possible to use animal sizes matched to the desired training difficulty. (3) Several training exercises may be performed with only a few centimeters of the animal and the remainder may be stored for future use. This was demonstrated by our studies, where only 91 animals were used for 150 exercises. (4) No anesthesia is required because the animal is killed before the procedure. In this context it is important to note that despite its death, the texture of the animal remains similar to that of the arterial wall. (5) The training can begin swiftly as no lengthy preparation is required. (6) Training can also be performed with magnifying glasses at home during the weekend if the surgeon is motivated.

In spite of the advantages mentioned above, there are some downsides in technique and methodology. First, a conventional patency test such as an O'Brian patency test is not possible. We used a permeability test as an alternative by injecting water into the earthworm using a syringe. A longitudinal incision allowed for visualization of the inner quality of the sutures for each training exercise. Second, adventicectomy, essential for obtaining patent microanastomosis, cannot be mimicked. Third, since the models are not followed over time, intimal injuries cannot be assessed. However, it was possible to assess the lumen of the vessel and control the inner injuries with a longitudinal incision of the earthworm. Fourth, the texture of the wall is similar to that of vertebrate arteries but is significantly different from that of veins. Moreover, only training exercises of end-to-side microanastomoses are presented here. Additional exercises that incorporate end-to-end microanastomoses and other techniques to manage size discrepancies (invaginating anastomoses, fishmouth incision, oblique section, and wedge excision) can be performed with this animal model. Current prospective studies are being performed in our laboratory. Finally, it is not possible to become familiar with alternative techniques of conventional microvascular microanastomoses such as laser $[16,17]$. Despite the above limitations, the simplicity, effectiveness, and low price all suggest that training with this animal model will significantly grow and develop in the near future.

\section{Conclusion}

The earthworm appears to be a reliable animal model for microsurgical training of end-to-side microanastomosis. Its numerous advantages discussed in this report all suggest 
that this training will significantly develop and grow in the near future.

Conflict of interest The authors have no conflicts of interest to disclose.

\section{References}

1. Maillard GF, Garey L (2006) Plastic surgery after ablative cancer surgery. Aesthet Plast Surg 30:47-52

2. Enajat M, Smit JM, Rozen WM et al (2010) Aesthetic refinements and reoperative procedures following 370 consecutive DIEP and SIEA flap breast reconstructions: important considerations for patient consent. Aesthet Plast Surg 34:306-312

3. Berger A, Bargmann HJ (1989) Aesthetic aspects in reconstructive microsurgery. Aesthet Plast Surg 13:115-120

4. Maillard GF, Garey LJ (1989) Immediate reconstruction after subcutaneous mastectomy. Aesthet Plast Surg 13:23-26

5. Aköz T, Akan M, Yildirim S (2002) If you continue to smoke, we may have a problem: smoking's effects on plastic surgery. Aesthet Plast Surg 26:477-482

6. Jacobson HH, Suarez EL (1960) Microsurgery in anastomosis of small vessels. Surg Forum 11:243-251

7. Leclère FM, Schoofs M, Mordon S (2011) Historical review and future orientations of the conventional vascular microanastomoses. Ann Chir Plast Esthet 56:232-240

8. Livingston CK, Ruiz-Razura A, Cohen BE (1999) Guidelines for a successful microsurgery training center and research fellowship. Plast Reconstr Surg 104:1555-1558
9. Crosby NL, Clapson JB, Buncke HJ, Newlin L (1995) Advanced non-animal microsurgical exercises. Microsurgery 16:655-658

10. Mantovani G, Fukushima WY, Baik Cho A, Aita MA, Mazzetti MV (2009) Use of earthworms for microsurgery training. J Reconstr Microsurg 25:275-278

11. Cooper EL, Roch P (1992) The capacities of earthworms to heal wounds and to destroy allografts are modified by polychlorinated biphenyls (PCB). J Invertebr Pathol 60:59-63

12. Cooper EL (1968) Transplantation immunity in annelids. Transplantation 6:322-337

13. Ilie V, Ilie V, Ghetu N, Popescu H, Grosu O, Pieptu D (2007) Assessment of the microsurgical skills: 30 min versus 2 weeks patency. Microsurgery 27:451-454

14. Lorenzo AR, Alvarez A, Garcia-Barreiro J, Centeno A, Lopez E, Martelo F (2006) Design and creation of an experimental program of advanced training in reconstructive microsurgery. Microsurgery 26:421-428

15. Leclère FM, Germain MA, Lewbart GA, Unglaub F, Mordon S, Louis D (2011) Microsurgery in liver research: end-to-side portocaval microanastomoses in dogfish. Clin Res Hepatol Gastroenterol 35:650-654

16. Leclère FM, Schoofs M, Buys B, Mordon SR (2011) $1.9 \mu \mathrm{m}$ Diode laser assisted vascular microanastomoses: experience in 40 clinical procedures. Lasers Surg Med 43:293-297

17. Leclère FM, Schoofs M, Buys B, Mordon SR (2010) Outcomes after 1.9-micron diode laser-assisted anastomosis in reconstructive microsurgery: results in 27 patients. Plast Reconstr Surg $125: 1167-1175$ 